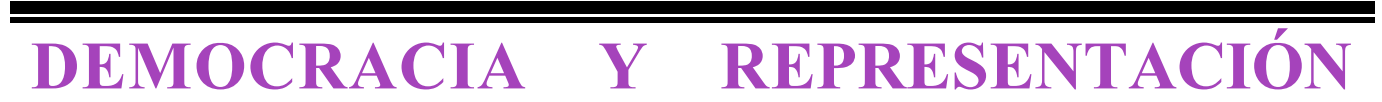




\section{PROBLEMAS DE ÁMBITO DE LA DEMOCRACIA}

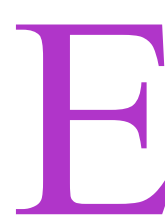

1 propósito fundamental de este escrito es suscitar algunos problemas y preguntas relativos a la justificación de quién, dónde y cómo se deben adoptar las decisiones democráticas. El texto se organiza en torno a tres preguntas. La primera pregunta a responder -y quizá sea de las pocas, entre las muchas que voy a plantear, que tiene una solución sencilla- es la que se refiere al título: ¿qué se entiende aquí por «ámbito de la democracia» y cuáles son sus problemas? Responderé inicialmente a la pregunta en dos partes: ¿qué entiendo por «ámbito» de un sistema de decisiones políticas?, y, en segundo término, ¿por qué limito el problema al sistema político democrático? Una segunda pregunta, de carácter conceptual, es la siguiente: ¿cuál es el alcance del asunto del ámbito o ámbitos de la democracia y por qué es difícil? En fin, la tercera pregunta pretende plantear algunos problemas de justificación ética del actual ámbito de la democracia, problemas que se intentarán ejemplificar en dos cuestiones interrelacionadas que pretenden mirar críticamente el ámbito estatal de la democracia: ¿hasta dónde y en qué términos deben llegar las decisiones democráticas en el área infraestatal o local y regional? ¿Y en el área supraestatal o internacional e, incluso, mundial?

\section{El ámbito de los sistemas políticos}

Lo que es el ámbito de un sistema político puede describirse y clasificarse de diversas maneras. La más sencilla es definirlo mediante los tres elementos que tradicionalmente se atribuyen al Estado, que ha llegado a ser la organización política por excelencia: la población, el territorio y la propia forma de organización jurídico-política. $\mathrm{O}$, situando esos tres elementos en una distinción tradicional en la teoría jurídica, análoga aunque no idéntica a la anterior, se trata de determinar el ámbito personal, 
el ámbito territorial y el ámbito material del sistema político y de las decisiones que lo caracterizan. Pues bien, se puede utilizar esos tres elementos para analizar el ámbito de las organizaciones políticas, poniendo por ahora entre paréntesis si esas organizaciones son estatales o no.

En primer lugar, la población, que presenta la pregunta de quién, qué personas deben decidir políticamente y sobre quiénes se debe decidir: por no insistir en la secular discusión sobre la mejor forma de gobierno, en la propia definición de la democracia ha sido un tema históricamente muy debatido qué personas deben estar llamadas a la tarea de tomar decisiones (o a la tarea de elegir a quienes deben tomarlas); y ha sido muy debatido, especialmente a lo largo del siglo XX, tanto en la teoría (recuérdese la institución del sufragio censitario o la defensa del voto desigual por parte de John Stuart Mill) como en la práctica, a través de las luchas por la ampliación del sufragio; si bien en la anterior vertiente se trata hoy de un problema prácticamente resuelto en el sistema democrático estatal por la institución del sufragio universal para los nacionales, todavía debe suscitar intereses teóricos la extensión del voto a los extranjeros y, como se verá, la fundamentación de la democracia cuando se pregunta por los sujetos de las decisiones políticas en sedes no estatales, por ejemplo, en algunas decisiones económicas de transcendencia pública $o$ en las internacionales. En cuanto a la pregunta por sobre quiénes pueden ser destinatarios de las decisiones, baste mencionar el problema de la afectación a las generaciones futuras.

El segundo ámbito, relativo al territorio, plantea varias preguntas relacionadas con el dónde y para dónde se deben tomar las decisiones políticas, con el espacio del poder político: ¿exclusivamente en el Estado, o también a nivel local y supraestatal?, ¿de manera privilegiada y definitiva por el Estado en todos los casos -con reserva de la soberanía- o también, soberanamente, al menos en algunos casos y materias, por organizaciones infra o supraestatales?; en fin, si se considera que el Estado no debe ser el único o el supremo centro decisorio, ¿cómo deberían tomarse las decisiones políticas en esos otros posibles ámbitos territoriales?, ¿con mayor democracia directa en el plano local?, ¿con un voto por individuo o, en cambio, por nación o Estado en el plano internacional?

El tercer ámbito, el relativo a la forma de organización política, al cómo gobernar, que entendido con amplitud comprende también la pregunta sobre qué materias se deben tomar las decisiones 
políticas, presenta diversos problemas «últimos» que merecen una mención: ¿cuál es la forma de organización política más justa (o menos injusta)?; dando por supuesto que se trata del sistema de gobierno democrático, ¿qué tipo de democracia?, ¿la directa, la representativa o una combinación de ambas?; una vez decidido el tipo, ¿qué sistema y qué criterios de votación han de seguirse (mayorías exigidas, posibles derechos de veto, valor de las abstenciones, representación proporcional o mayoritaria, etc.)?; y, ulteriormente, ¿cuál debe ser la extensión del poder político democrático?, o, de otro modo, ¿debe extenderse, y cuánto y cómo, el control político democrático a ámbitos tradicionalmente ajenos o distintos de él, como las empresas -locales, nacionales, o multinacionales-, el aparato judicial y burocrático, o el sector de la influencia ideológica (prensa, enseñanza, etc.)?

Hasta aquí unas cuantas preguntas -no exhaustivas, desde luego- que pueden servir para situar el significado del término «ámbito». Demasiadas preguntas, se dirá. Demasiado complejas también, entre otras cosas porque se entrelazan en los tres ámbitos, admiten respuestas diferentes y sugieren justificaciones y límites no sólo estricta y puramente democráticos, sino también, por ejemplo, liberales, como ocurre con la división de poderes. Preguntas, en fin, demasiado complejas como para intentar responder incluso a cada una por separado y no ya a todas a la vez. No voy a intentar, ni mucho menos, abordarlas todas

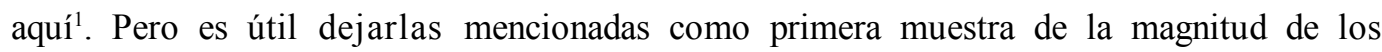
problemas suscitados por la aparentemente simple pregunta sobre el significado del ámbito del sistema político.

Había quedado pendiente responder a la segunda parte de la pregunta inicial: ¿por qué limitar el análisis al ámbito del sistema político democrático? Sencillamente, porque asumo y presupongo que la democracia es aceptable como sistema de gobierno justo o, mejor, como sistema más justo que ningún otro existente, por más que pueda no ser la perfección suma, sobre todo en la práctica. Aunque la discusión sobre el ámbito de la democracia permitirá más adelante matizar algunos de estos presupuestos preliminares, no estará de más precisar que entiendo por

${ }^{1}$ Dos análisis meditados y profundos sobre buena parte de estos problemas pueden encontrarse en Norberto Bobbio, «La regola di maggioranza; limiti e aporie», y Claus Offe, «Legittimazione politica mediante decisione di maggioranza?», ambos en el libro colectivo Democrazia, maggioranza e minoranze, Bolonia, Il Mulino, 1981, págs. 33-72 y 73-98, respectivamente. 
democracia el método de gobierno que se caracteriza por el consenso de los ciudadanos expresado en un sistema de libertades y a través del derecho efectivo a la participación popular en la adopción de las decisiones políticas según la regla de mayoría. Añadiré que uso y usaré el término «decisión» en su significado más amplio, comprensivo no sólo de tomas de posición concretas, sino también de normas y principios generales.

Dentro de tal caracterización de la democracia, se incluye la participación popular indirecta a través de elecciones periódicas, de modo que asumo y doy por supuesta la suficiente justificación de la democracia representativa de tipo occidental. En cambio, y sin que haga falta citar a las «democracias orgánicas», son radicalmente deficitarias respecto al mínimo exigible las llamadas democracias populares, al menos tal y como han venido funcionando hasta la presente oleada de reformas en varios países del oriente europeo. Desde estos presupuestos iniciales favorables a la democracia de impronta liberal, se limita un poco la pregunta por cuál debe ser el ámbito del sistema político, pues se niega de antemano que, respecto al quién y al cómo, la respuesta pueda ser que debe decidir un dictador o un comité central no elegido democráticamente, así como se rechaza también que la propia organización política deba ser autoritaria o despótica. Sin embargo, aun dentro de la fundamentación democrático-liberal, los problemas a plantear siguen siendo grandes y complejos, pues afectan al alcance y a los límites de las decisiones políticas en este tipo de legitimidad.

\section{Alcance y dificultades del ámbito de la democracia}

La segunda pregunta pendiente era: ¿cuál es el alcance de este asunto del ámbito de la democracia y por qué resulta especialmente difícil? De entre las varias justificaciones del sistema democrático, considero fundamental la que se apoya, entre otras cosas, en el juicio de valor último de que toda persona tiene derecho a decidir sobre lo que le afecta. De ese juicio de valor, que expresa la creencia en la relevancia de la autonomía individual, se deriva lo que estimo el fundamento básico de la democracia: que en principio toda persona tiene derecho a participar en la adopción de las decisiones colectivas que le afectan ${ }^{2}$. Bajo

${ }^{2}$ No es en absoluto casual que un kantiano como Karl Otto Apel haya podido insistir en la conexión necesaria entre la consideración de los intereses de todos los afectados y el respeto a la autonomía moral individual como presupuesto 
el anterior supuesto, dejo a un lado toda discusión sobre las múltiples y difíciles aristas que presenta el problema de la justificación de la democracia ${ }^{3}$. En cambio, no puedo pasar por alto que el concepto de «afectado» es en principio tan ambiguo e impreciso que puede resultar formal o vacío: al igual que ocurre con la célebre definición de justicia, «Dar a cada uno lo suyo», necesita contenidos concretos para significar algo sustancial. Esa determinación no creo que pueda intentarse de modo genérico y abstracto, sino en conexión con circunstancias históricas y sociales específicas y variables, cuyas indicaciones de márgenes, reglas y excepciones no pueden aspirar a ofrecer más que criterios de razonabilidad, no apodícticos, sino de más o menos, en el sentido de la doxa aristotélica. No obstante, con antelación a esas determinaciones concretas, cabe sugerir al menos dos generalizaciones sobre el concepto de «afectado» en el contexto de la adopción de decisiones.

La primera generalización es que con tal concepto puede plantearse una disyuntiva paralela a la de una polémica bien familiar

a priori de la moralidad (cfr. «El a priori de la comunidad de comunicación y los fundamentos de la ética. El problema de una fundamentación racional de la ética en la era de la ciencia», en $L a$ transformación de la filosofía, II, El a priori de la comunidad de comunicación, trad. cast. de A. Cortina, J. Chamorro y J. Conill, Madrid, Taurus, 1985, pág. 426; así como Estudios éticos, trad. cast. de Carlos de Santiago, Barcelona, Alfa, 1986, págs. 117, 201-202 y 215 (naturalmente, lo que asumo en el texto no compromete a aceptar necesariamente esa tesis de Apel u otras conectadas con ella).

${ }^{3}$ Entre la abundantísima bibliografía al propósito no me resisto a citar el libro de William N. Nelson, La justificación de la democracia (Barcelona, Ariel, 1986; ed. orig., 1980), donde se critica con harta ligereza el intento de justificar la democracia por el valor intrínseco del derecho a la participación de los afectados por las decisiones colectivas, intento que, según Nelson, no es «verosímil» porque «(e)stá claro que muchas personas disfrutan de la actividad política, pero no lo es menos que para otras es absolutamente desagradable» (pág. 43). Por lo que pueda servir de ampliación o aclaración de lo afirmado en el texto sobre este asunto, no estará de más mencionar tres falacias detectables en la objeción de Nelson; a) lo que está en cuestión es el valor del derecho a la participación y no el de la participación misma, entre otras razones porque no ejercer formalmente tal derecho (no votando, por ejemplo) puede ser una forma más de participar políticamente; $b$ ) el valor intrínseco de la democracia, como el de la libertad de expresión o de religión, no depende de que todas las personas, y ni siquiera la mayoría, lo aprecien o lo reconozcan, salvo que uno se obligue a justificar eventuales estados de esclavitud feliz; c) el disfrute subjetivo de la participación política, y aun del derecho a la participación, y, más en general, criterios como los de utilidad o felicidad no son la única fuente posible de contraste del valor de la autonomía, sea individual o colectiva, como sobradamente lo muestra la filosofia práctica kantiana. 
en la teoría de los derechos subjetivos: si es afectado bien quien tiene un interés o necesidad, porque recibe un beneficio o perjuicio, o bien quien es capaz de manifestar su voluntad tanto fáctica como normativamente, es decir, quien tiene fácticamente y debe tener normativamente (en seguida especificaré en qué sentido) capacidad o poder para decidir en la materia. A mi modo de ver, la disyuntiva es falsa porque uno y otro rasgo sirven como condiciones necesarias de la afectación que da título para la participación en la toma de la respectiva decisión. Cierto que la exigencia de tener un interés o necesidad parece inescindible de la idea de estar afectado por alguna acción o circunstancia. Sin embargo, aun siendo necesaria, la presencia de un interés o necesidad no es suficiente para tener título a decidir en cuanto afectado, como lo prueba, por un lado, la existencia de menores o la posibilidad de generaciones futuras con intereses y necesidades relevantes, a quienes no se puede pedir opinión, y, por otro lado, la razonabilidad de que ciertas interferencias en intereses de terceros no autorizadas por éstos sean subsanables sólo mediante indemnización o algún mecanismo similar. De ahí que también la exigencia de que exista capacidad fáctica y normativa de manifestar la propia voluntad parezca necesaria para participar en la adopción de decisiones sobre lo que a uno le afecta. Bien entendido que el tipo de capacidad normativa relevante en este escrito es la moral y no la jurídica o cualquier otra meramente social, de manera que el detentar de hecho o el tener jurídicamente reconocida la capacidad de actuar sobre determinados intereses no necesariamente ha de entenderse que implica que se merezca moralmente tal reconocimiento.

La segunda generalización que cabe formular se refiere a la necesidad de una mínima determinación previa de quienes pueden ser los afectados. Dada la variedad y multiplicidad de intereses y necesidades humanas, siempre será posible encontrar afectados remotos respecto de casi cualquier acción y situación, que es la vía por la que la pérdida de una espuela termina «explicando» la pérdida de un reino. Evitar ese tipo de entrelazamientos indirectos anima a diferenciar entre distintas formas de afectación que permitan enmarcar sólo para los casos relevantes el concepto de afectados con título a la participación. En versiones previas de este texto sugerí como diferencia plausible la basada en la distinción de Dworkin entre preferencias personales y externas, según una decisión se refiera a intereses propios en exclusiva o a intereses ajenos, altruistas o no. Sin embargo, la extremada rareza en la práctica de intereses puramente personales, entre los que no parecen encontrarse los intereses colectivos y los 
generales, obliga a revisar esa propuesta ${ }^{4}$ En cambio, aunque inevitablemente vaga, probablemente sea más prometedora la menos novedosa distinción entre intereses directos e indirectos, de modo que sólo los primeros se considere que afectan relevantemente a las personas en cuestión. Desarrollar esta sugerencia con detalle, sin embargo, exigiría un escrito diferente.

Tras las dos precisiones anteriores, es ya momento de presentar algunas de las implicaciones del principio básico de la democracia, de que cada uno tiene derecho a participar en las decisiones colectivas que le afectan. Este principio se suele entender, en primer lugar, en referencia a decisiones que pueden llamarse simples o de primer nivel, es decir, decisiones que tienen consecuencias directas en la realidad (si se debe permanecer o no en una alianza militar, si debe despenalizarse o castigarse el aborto, si es preferible esta política económica o aquella otra, etc.). Sin embargo, para que el principio sea válido y completo es imprescindible también, en segundo lugar, que el derecho de participación alcance a decisiones de segundo nivel -o, por así llamarlas, ya que son lógicamente superiores o previas, «metadecisiones»-, es decir, a las decisiones que no afectan directamente a la realidad sino al propio ejercicio del derecho de decisión: son las decisiones a propósito de si se debe, y cuándo, tomar una decisión (si se decide o no poner en cuestión la permanencia en una alianza militar, si se decide o no reformar la ley del aborto, si se decide o no cambiar de política económica...). Es lo que Robert Dahl ha llamado el «control de la agenda» ${ }^{5}$. Y por cierto, que este derecho a participar en las decisiones de segundo nivel es

${ }^{4}$ La distinción de Dworkin puede verse en «Reverse Discrimination», The New York Review of Books, 1976, § 4; ahora también en Taking Rights Seriously, London, Duckworth, 1978, cap. 9, § 4 (hay trad. cast. de éste, de Marta Gustavino, Los derechos en serio, Barcelona, Ariel, 1984) y en «Do We Have a Right to Pronography?», Oxford Journal of Legal Studies, 1981, núm. 1; también, por donde se cita, en A Matter of Principle, Oxford, Clarendon Press, 1985, págs. 359-372. Un escrito dedicado a impugnar la distinción de Dworkin es el de John Hart Ely, «Professor Dworkin's External/Personal Preference Distinction», Dike Law Journal, 1983, vol. 5, november, págs. 959-986; en castellano, una síntesis de distintas críticas, propias y ajenas, en Diego M. Farrell, «Dworkin y el utilitarismo; algunas inconsistencias», Doxa, Cuadernos de filosofía del derecho, núm. 2, 1985, págs. 187-195 (también yo mismo me ocupo con mucha mayor amplitud de esta distinción en un libro en preparación, de probable título Discriminación inversa e igualdad).

${ }^{5}$ Cfr. «Procedural Democracy», en Laslett, Peter y Fishkin, James (comps.), Philosophy, Politics and Society, Fifth Series, Oxford, Basil Blackwell, 1979, págs. 105-108. 
imprescindible, pues sin él la legitimidad democrática sería un fraude. Sólo si puedo determinar que algo me afecta -y en esa posibilidad de determinación está la decisión de segundo nivel-, de modo que ponga en marcha el mecanismo para adoptar una decisión sobre ello -y esta otra decisión es ya de primer nivel-, participo en un sistema democrático. $\mathrm{O}$, por dar un ejemplo, si no tengo el control de la agenda, estoy en el caso de los hijos de una familia en la que son los padres quienes deciden qué estudios se deben seguir, cómo gastar el dinero o cuándo se debe ir al cine o salir a la calle; aunque esporádicamente los padres permitan a los hijos decidir en algunas cosas (supongamos, dónde hacer las vacaciones), no son los hijos quienes tienen el derecho de decisión propiamente dicho, como tampoco se puede decir que tal sistema de organización sea democrático: más bien es la representación típica del poder patriarcal o paternal, que cuando se traslada a la política caracteriza al poder despótico.

La distinción anterior -y especialmente el concepto de decisión de segundo nivelpermite mostrar dos cosas. En primer lugar, una característica general de las decisiones que ha de tenerse presente: las decisiones pueden adoptarse no sólo de modo expreso, sino también -con tal de que exista capacidad y voluntad- tácitamente, es decir, por omisión. Al igual que cuando se vota en un referéndum se participa en la decisión tanto votando «sí» como votando «no», en las decisiones de segundo nivel se participa en la decisión tanto si se decide decidir como si se decide no decidir sobre una cuestión. Naturalmente, para ello es preciso tener, primero, capacidad o posibilidad -física y normativa, usualmente capacidad jurídica- de tomar tal tipo de decisión; y, segundo, voluntad de tomarla, lo que implica consciencia de su posibilidad y oportunidad. Estas dos condiciones son necesarias, pues pueden existir asuntos no decidibles para un determinado colectivo o sobre los que, aunque exista la capacidad, ni siquiera se piensa que, al menos de momento, puedan ser objeto de decisión: el primero es un caso de falta de capacidad (por ejemplo, en nuestro sistema jurídico, una comunidad autónoma no puede decidir si emitir moneda o no) y el segundo de falta de voluntad (por ejemplo, en nuestro país, y en la actualidad, la inexistente decisión de reformar la Constitución). Dadas esas dos condiciones, parece que pueden tomarse decisiones por omisión, lo que es especialmente claro en las de segundo nivel -en las de primer nivel, en cambio, aparece con más virulencia el problema del significado de la abstención, que, como el del silencio en el Derecho, suscita interpretaciones contradictorias; 
pero no me entretendré en este problema-: si ante unas elecciones un partido propugna bajar los impuestos y otro no dice nada sobre el asunto, la gente interpretará, y con razón, que ambos han tomado una decisión sobre el problema y que la del segundo partido significa que, en el mejor de los casos, los impuestos no bajarán, es decir, que las cosas seguirán igual. Y, como en este ejemplo, en la mayoría de las ocasiones, precisamente, las decisiones por omisión consagran el status quo, pero no por eso dejan de ser tan decisiones como las que intentan cambiarlo.

En segundo lugar, la distinción entre los dos niveles de decisión permite entrar de lleno en el problema del ámbito de la democracia porque ayuda a comprender que el principio democrático básico, el derecho a la participación, presupone un conjunto de decisiones lógicamente previas a los dos tipos anteriores, es decir, que se trata de decisiones de tercer nivel o meta-metadecisiones. Son las decisiones que suministran el marco imprescindible en el que actuar democráticamente o, con otra formulación, que proporcionan las reglas últimas y principales del juego democrático: precisamente, las decisiones a propósito del triple ámbito relativo a quién, dónde y cómo de la decisión política, es decir, de los sujetos que deben decidir y sobre los que se puede decidir, del espacio territorial en el que y sobre el que se debe decidir y, en fin, de la forma de decidir, que comprende la determinación de las materias sobre las que se puede o no se debe decidir. En muchos casos, las decisiones sobre el ámbito de la democracia se adoptan de manera expresa, típicamente -como prueba de su importancia- mediante normas constitucionales. En otros casos, en cambio, determinados elementos de ese triple ámbito se adoptan implícitamente, tratándose de decisiones por omisión. Así como la reserva de un área de derechos exenta en principio de la decisión democrática suele decidirse expresamente (por ejemplo, los derechos de libertad o de propiedad privada y libre empresa), la determinación del ámbito territorial suele presuponerse y basarse en la historia o la tradición, como lo ejemplifican las fronteras de América latina. Pero tanto en uno como en otro caso se plantea el problema de cómo justificar esas decisiones: ¿deben legitimarse a su vez democráticamente?; es decir, ¿debe aplicarse a tales decisiones de tercer nivel el principio de que cada uno tiene derecho a participar en la toma de las decisiones colectivas que le afectan, como hemos visto que sí debe ocurrir para las decisiones de primero y de segundo nivel? Este es el problema.

A primera vista parece que es tan innecesario justificar democráticamente esas decisiones de tercer nivel como innecesario es 
legitimar democráticamente el propio principio de que cada cual tiene derecho a participar en la decisión de lo que le afecta. Con tal que las cuestiones por decidir en el ámbito marcado -que serían las de primero y segundo nivel, no las de tercer nivel- se circunscriban a los afectados y éstos participen en ellas, tan democrática es una familia como un partido político, una comunidad religiosa como un cártel industrial o un sindicato como un Estado, y el quién vota es bien diferente en cada caso, sin que su determinación provenga necesariamente de una decisión previa por parte de los afectados; por su parte, igual de democráticas pueden ser las decisiones que se toman en un pequeño pueblo, en una universidad, en un gran Estado o en una organización internacional, y el territorio es bien diferente, siendo establecido o señalado en ocasiones por una instancia ajena; o, en fin, democráticos son -no voy a entrar aquí en el problema de si más o menos- la decisión a concejo abierto en Castilla, el abundante uso del referéndum en Suiza, el sistema electoral mayoritario inglés y el proporcional italiano, sin que quepa duda de que se trata de formas bien distintas de ejercer la democracia que pueden haber sido establecidas no por decisión democrática expresa, sino por la tradición o por decisiones más o menos autoritarias.

No puede negarse que en muchos casos, tal vez en la mayoría, el ámbito en el que se ejerce la democracia es aceptado de hecho como suficientemente legítimo, se haya o no decidido democrática y expresamente sobre él; que sean los irlandeses, y no, por ejemplo, el parlamento europeo, quienes decidan no autorizar el divorcio en Irlanda, que los italianos no se planteen reformar su sistema electoral o que en todos los sistemas democráticos conocidos se excluya de la toma de decisiones a colectivos eventualmente interesados, como son los extranjeros residentes o los menores de edad, no parece que ponga en cuestión la legitimidad democrática de tales decisiones, al menos de hecho (lo que no impide que pueda ser discutida críticamente, por ejemplo al modo como se sugiere en la siguiente y última parte de este escrito).

Sin embargo, no siempre ocurre así. Hay otros casos en los que la determinación del ámbito de la democracia aparece como claramente ilegítima, sin que el hecho de que tal determinación se produzca a través de una decisión democrática sirva para subsanar el defecto, es decir, que hay casos de decisiones democráticas sobre el ámbito que son injustificables. Considérense los siguientes ejemplos, en los que la legitimación democrática es insuficiente o aparente: que los varones de un país nieguen durante largo 
tiempo el derecho de sufragio femenino a sus conciudadanas, que el presidente de un gran país, elegido democráticamente, presione de tal modo que consiga que un tercer país instale misiles nucleares contra la voluntad de la mayoría de la población afectada, o, en fin, que una nación elija democráticamente a un dictador fanático que fulmina el sistema democrático, no justifica ninguna de tales decisiones, que ejemplifican, respectivamente y de manera indicativa, decisiones relativas al quién, al dónde y al cómo se debe decidir, es decir, decisiones sobre el ámbito de la democracia. Como se puede observar, estos son problemas graves e importantes y, de nuevo, complejos. Prueba de su complejidad es que la razón de la ilegitimidad es distinta en cada uno de los tres ejemplos: en el primero -que es el caso suizo hasta 1971- porque decide sólo una parte de los afectados, siendo a todas luces culpable de parcialidad y discriminación hacia la otra mitad de la población; en el segundo ejemplo -que es el caso holandés de la instalación de los euromisiles en el invierno de 1984- porque un tercero decide contra la voluntad de los principales afectados; y en el último ejemplo -que es, con más o menos matices, el caso Hitler- porque una decisión democrática que acaba con las libertades básicas es ilegítima, como mínimo, por violar el derecho de las minorías afectadas a disentir y a participar.

Naturalmente, se podrían buscar otros muchos ejemplos en los que se entremezclen más todavía los tres ámbitos: la agresión armada o la incitación al golpe de Estado en un país por parte de otro, la emisión de polvo radiactivo tras las pruebas nucleares, la negación o limitación de los derechos políticos a una minoría racial (y no digamos a una mayoría, como ocurre en Sudáfrica), el castigo grave de toda forma de objeción de conciencia, el establecimiento de discriminaciones sexuales en el trabajo, la supresión de un mínimo de bienestar para minorías como ancianos, minusválidos, parados, etc., o el acuerdo de que las disputas científicas han de decidirse por la mayoría de la población. Aun en el caso de que todas esas decisiones fueran tomadas por órganos y procedimientos democráticos, ¿no pondrían de manifiesto bien una mala interpretación y aplicación del principio democrático, bien importantes limitaciones del mismo? Ejemplos como los anteriores ilustran dos puntos relevantes con cuyo comentario concluiré esta parte del escrito.

El primer punto está en que el principio democrático no agota los criterios de legitimidad y de justicia. Desde luego, cuando el principio se interpreta severamente -incluyendo el respeto a las minorías y la garantía de determinados derechos básicos, 
como insiste Elías Díaz - es el mismo principio democrático el que excluye la legitimidad de hechos como la agresión armada a otro país, las pruebas nucleares o la limitación de derechos políticos a cualquier minoría. Pero aun así, existen al menos dos tipos de razones que matizan o limitan el propio principio: primero, la existencia de derechos básicos que son válidos al margen de su reconocimiento por la mayoría y cuya violación no pone en riesgo, en principio, la limpieza del propio juego democrático (por ejemplo, los derechos a la igualdad y a la libertad en esferas no políticas, como la igualdad laboral y la justicia fiscal o la tolerancia en materias religiosas y hacia determinadas formas de objeción de conciencia); y, segundo, la misma posibilidad o, por lo menos, la eficiencia suficiente de determinadas instituciones (por ejemplo, la cooptación del profesorado, cuyo carácter aristocrático u oligárquico parece defendible, o la organización militar y sanitaria, cuyo carácter no democrático resulta funcional).

El segundo punto ilustrado por los ejemplos anteriores es que la justificación de la democracia y de su ámbito depende del contenido de tal justificación y no de la forma o método utilizado, sea democrático o no, ya que en el mejor de los casos tal método será insuficiente, y en el peor, injusto. Es más, existen casos en los que es lógicamente imposible o absurdo pretender obtener una decisión democrática sobre problemas de ámbito. En un extremo acecha el recurso al infinito -en términos castizos, el cuento de nunca acabar-, como ocurre a veces en los procedimientos, en el cómo se decide, donde a falta de reglas previas siempre es posible poner a discusión el modo de votación, elevar después el debate a cómo se debe votar sobre el modo de votación y así sucesivamente: personalmente, recuerdo como típica de muchas asambleas de facultad la propuesta de «se vota si se vota»..., por ejemplo, una huelga. En el otro extremo, aparece un mecanismo alternativo que también la lógica condena, el recurso al círculo -popularmente, la pescadilla que se muerde la cola-, como si, respecto a la determinación de los sujetos, del quién decide, se formulara la absurda propuesta de que los afectados decidan sobre quiénes son los afectados, lo que exigiría que alguien decidiera previamente quiénes son los primeros afectados llamados a votar, de modo que sobraría la decisión de éstos: recuerdo también aquí que la última ley sindical

${ }^{6}$ Así, por ejemplo, en su último libro, De la maldad estatal y la soberanía popular, Madrid, Editorial Debate, 1984, cap. I, $\S 4$. 
franquista incurría en un recurso de este tipo -que Kelsen llamaba «lagunas técnicas»- al decir, en un precepto, que el consejo sindical debía nombrar a su presidente y, en otro precepto, que el tal consejo se debería constituir a convocatoria de su presidente, de modo que el consejo no se podía constituir ni su presidente ser elegido (ignoro cómo se solucionó la paradoja, aunque sospecho que debió ser el poder político quien realmente eligió tanto al consejo como a su presidente).

\section{Problemas de justificación: de la democracia local a la democracia mundial}

Si la justificación de los criterios de determinación del ámbito de la democracia no está, de manera última al menos, en el propio principio democrático, me ceñiré al análisis de esa justificación en dos campos que comprenden algunos de los muchos elementos que, como hemos visto, conforman tal ámbito. Esas dos áreas problemáticas toman como punto de referencia fundamental el sistema político democrático estatal: por abajo, el área de la democracia infraestatal, que se refiere principalmente al ámbito local y regional, y, por arriba, el área de la democracia supraestatal, que se refiere fundamentalmente al ámbito de la incipiente y posible democracia en el nivel internacional. Sería interesante tocar también el área de la democracia paraestatal, referida por ahora a un ámbito en buena parte «extrapolítico»y, con mayor razón, extrademocrático: el segmento de la economía, que no sólo coexiste horizontalmente con el Estado, sino también -basta mencionar las empresas multinacionales- con el área supraestatal. Sin embargo, aunque sólo sea por razones de extensión, soslayaré este problema ${ }^{7}$.

Si las áreas local e internacional tienen como punto de referencia central el marco estatal, la justificación de tal marco merece algún comentario. A fin de cuentas, salvo Atenas y algunas pocas excepciones más, el Estado nacional es el reducto típico donde se viene practicando el juego democrático; y eso sólo en los contados Estados en que se practica y -para ser francamente generoso- desde finales del siglo XVIII. Esta reducción básica del ámbito de la democracia de los modernos al área estatal-nacional no es, por cierto, una elaboración racional especialmente

${ }^{7}$ Sobre este asunto me limito a recomendar un libro de Robert Dahl en buena parte dedicado a él, Dilemmas of Pluralist Democracy. Autonomy vs. Control, New Haven-London, Yale University Press, 1982. 
justificada, sino un dato complejo transmitido por la historia y asumido cultural y normativamente. No es difícil exagerar la importancia y la gravedad de la división en Estados tendencialmente nacionales que pretenden la soberanía -en palabras de su primer formulador, Bodino, «la puissance absolue et perpétuelle»- hacia el interior y hacia el exterior. Sin embargo, no siempre se cae en la cuenta de que tal reducción a ese ámbito, y su consiguiente atribución de soberanía al Estado, suministra implícitamente no sólo una respuesta al problema del dónde y para dónde se debe gobernar, sino también a la pregunta estrechamente conectada del quién, que constituye el primero y más decisivo problema que el ámbito de la democracia plantea: ¿quiénes son los afectados?

Que esa doble pregunta por el dónde y el quién se ha tendido a responder implícitamente -salvo, quizá, en las justificaciones nacionalistas y románticas del poder- lo muestra ejemplarmente la doctrina de Thomas Hobbes. Hobbes, al igual que Maquiavelo o Bodino, en ningún momento de su obra apela de forma explícita a la idea de nación o nacionalidad como condición del Estado ${ }^{8}$. Y, no obstante, sin un concepto de nación, sea amplio o estricto, es imposible entender y enmarcar la propuesta hobbesiana de justificación del Estado, una doctrina en la que los individuos (y subrayo la idea de «individuos», que hace referencia al colectivo de la humanidad) acuerdan constituir el cuerpo político y ceder su poder a un soberano común, convirtiéndose con ello en ciudadanos (y subrayo ahora la idea de «ciudadanos», que son los pertenecientes no a la humanidad, sino, precisamente, a una comunidad política determinada y limitada). En esa transformación contractual, si no se presupone que la comunidad política es la constituida históricamente -es decir, la que llegaría a ser, con diferentes variaciones y nunca sepultadas reivindicaciones, la nación- el esquema hobbesiano pierde sus puntos de referencia. Piénsese que cualquier grupo político dotado de un jefe soberano y con cierto poder efectivo en una población y un territorio sería formalmente un Estado, con independencia de que se mantuviera en competencia o guerra con grupos exteriores. Sin esa referencia al ámbito territorial nacional, y por ejemplificarlo con una dramática situación actual, Líbano -en especial su capital-, no sería tanto, paradójicamente, una perfecta representación del puro estado de naturaleza hobbesiano, de guerra total y sin fin de todos contra todos, como un

${ }^{8}$ Cfr. Alessandro Passerin d'Entrèves, La dottrina dello stato. Elementi di analisi e di interpretazione, 2. ${ }^{\mathrm{a}}$ ed., Torino, Giappichelli, 1967, págs. 241-242. 
conjunto de pequeños Estados en ese estado de naturaleza externo de guerra internacional entre sí.

Así pues, el Estado, o, mejor, los Estados presuponen unas fronteras territoriales y una población, es decir, presuponen el fenómeno de la nación, entendida esta palabra en uno de sus sentidos más genéricos y menos inmanejables. No me detendré en el importante problema de si en la actualidad asistimos a un declive de las nacionalidades históricas y a un retorno de los particularismos ${ }^{9}$. También doy por supuesto que la existencia de las naciones viene dada por la historia, una historia no siempre forzosamente lejana y -casi no hace falta recordarlo- tantas veces surcada por guerras, conquistas, repartos y anexiones, en suma, por el uso y abuso de la fuerza. Nada de todo ello impide que el área territorial y poblacional común a la mayoría de los Estados -que dentro de grandes oscilaciones tiene grandes dimensiones- aparezca, en principio y a toro pasado, como más justo y eficaz para la cobertura de las enormes necesidades sociales actuales que hipotéticos modelos de dimensiones más reducidas, como la ciudad-Estado, las pequeñas repúblicas italianas del Renacimiento o los casos monegasco, luxemburgués y similares. El problema hoy parece más bien si las dimensiones de los Estados no se han quedado pequeñas para afrontar los grandes retos pendientes de la humanidad, de los que los dos más graves son el peligro bélico y el hambre. En definitiva, al hablar de humanidad, surge inmediata la pregunta de si hoy, en un mundo tan interdependiente, no somos todos afectados, ya que no por absolutamente todas, sí por buena parte de las decisiones que se adoptan en distintas esferas y territorios. Bajo estos presupuestos, veamos el proceso de justificación que va de la democracia local a la democracia mundial.

Comenzaré por el área infraestatal o local en sentido amplio; éste comprende las regiones y naciones integradas en Estados territorialmente más amplios y a las que, por comodidad, unificaré terminológicamente en adelante como regiones sin más. Analizaré tres preguntas generales: en primer lugar, la más grave, la justificación de quiénes deben decidir, que plantea el doble problema del derecho a la autodeterminación de los pueblos y el de los conflictos entre regiones que pertenecen a un Estado más amplio; en segundo lugar, la pregunta por la justificación del cómo debe organizarse la autonomía -término que aquí no

${ }^{9}$ Véase sobre ello un jugoso artículo de Francisco Murillo Ferrol, titulado precisamente «La nación y el ámbito de la democracia», Sistema, núm. 26, sept. 1978, págs. 3-19. 
equivale a independencia soberana- regional y local; y, en fin, una pregunta relativa al dónde deben tomarse algunos tipos de decisión que atribuyen especiales cargas y beneficios a áreas locales determinadas.

Hoy, prácticamente superada la descolonización política, el derecho a la autodeterminación de los pueblos sigue teniendo cierta significación para algunas naciones integradas en Estados multinacionales. En último término, el problema es siempre relativo a quienes deciden y, como ya he sugerido antes, creo que la justificación democrática no puede dar razón en exclusiva ni por completo de la soberanía estatal, al menos en un mundo tan interrelacionado como el nuestro. Pero, en principio, y en tanto se justifique la existencia de Estados independientes, no me parece que haya razón democrática alguna -más bien al contrario- para negar la justificación de la posibilidad de obtener la soberanía por parte de un pueblo o nación que así lo desea. Esto significa que, según el principio democrático, parece que debe preferirse el derecho de una minoría étnica, religiosa, etc., que se desea a sí misma como Estado independiente al posible derecho de la mayoría en la que aquella comunidad está previamente integrada. Ahora bien, el problema no puede despacharse en cuatro frases, dada su gravedad y complejidad; basta pensar en una pequeña parte de la historia centro-europea, como la del imperio austro-húngaro en los dos últimos siglos, para darse cuenta de ello ${ }^{10}$.

Por un lado, es claro que para preferir el derecho de una comunidad sobre el de otra tiene que desear libremente la independencia la mayoría de la comunidad separatista (la mayoría de la minoría, en términos del Estado preexistente). Y es igualmente claro que no basta la voluntad de una minoría (una minoría de la minoría, se entiende), quizá violenta, que pretenda representar un espíritu del pueblo metafísico al margen de la voluntad real de la mayoría o, peor, a una parte parcialmente significada (por motivos racistas, por ejemplo) del total de los efectivos habitantes -y, por tanto, primeros afectados- del territorio en cuestión.

Por otro lado, de las tres formas típicas de resolución de conflictos de autodeterminación, la aplicación del principio democrático no es forzosamente y en todos los casos, ni mucho

${ }^{10}$ Para una descripción de este caso, en relación con las doctrinas y propuestas de Karl Renner y Otto Bauer, véase Manuel García Pelayo, El tema de las nacionalidades. La teoría de la nación de Otto Bauer, Madrid, Editorial Pablo Iglesias, 1979, esp. págs. 1-6. 
menos, la panacea, y ni siquiera la solución menos mala. Aparte de las dificultades que puede introducir la distribución aleatoria de distintas comunidades nacionales en un mismo territorio, una aplicación mecánica del criterio democrático en este campo puede provocar una enorme disgregación social y gravísimas heridas producidas por la división radical entre comunidades diferenciadas pero no necesariamente hostiles. Todo ello inclina a estimar preferibles los acuerdos entre las distintas poblaciones implicadas, como ejemplifican los sistemas federales y similares: es la solución del pacto, que no sigue el principio de mayoría, típico de la democracia, sino el de unanimidad o, si éste es inviable, el del consenso. De todas formas, cuando el acuerdo se muestra imposible, el método democrático parece el más justificado, pues el tercer método, el recurso a la violencia, es incomparablemente más injusto, dañino y costoso que los anteriores, al menos, y sin margen de duda, cuando existe previamente un marco democrático suficiente, que, por tanto, respete a las minorías nacionales. En todo caso, el recurso a la violencia extrema se produce generalmente por la exasperación ideológica y puramente irracional entre el nacionalismo regional que es capaz de todo para conseguir la separación y el nacionalismo estatal dispuesto a la guerra y a la dominación para mantener la unidad. Y aunque luego -como enseñan, respectivamente, la guerra de secesión americana y las revoluciones anticolonialistas- la historia pueda dar la razón al vencedor, sea el que sea, ¿estamos seguros de que esa «razón» justifica de verdad?

La pregunta por el quién debe decidir en los ámbitos locales afecta también a un problema relacionado con el anterior, acaso menos grave pero no menos importante. Me refiero a los conflictos de inclusión y exclusión recíproca de dos o más comunidades en donde no se pone en cuestión la existencia de un aparato soberano común o superior a ambas. Supongamos que una localidad quiere pertenecer al ayuntamiento de otra y que la otra no desea tal incorporación o que de dos localidades que pertenecen al mismo ayuntamiento una desea separarse y la otra continuar unida. ¿Quiénes deben ser los afectados llamados a decidir en este tipo de casos? Cuando las decisiones afectan a la demarcación política de dos comunidades parece que sigue siendo preferible el pacto o acuerdo -unanimidad o consenso, recuérdese, y no criterio de mayoría-, acuerdo como el que se produce si se exige la aprobación por separado de una mayoría cualificada de cada una de las dos comunidades. Una vez más, el criterio democrático por sí solo se muestra insuficiente, pues globalizar la adopción de la decisión entre las dos comunidades (por ejemplo, 
mediante un referéndum con un cuerpo consultivo único e indiferenciado de ambas), comporta el riesgo de que una gran mayoría de una comunidad prevalezca sobre una gran mayoría de la otra. En todo caso, puesto que aquí está excluido de hecho el recurso a la violencia, el planteamiento y la resolución de este tipo de conflictos sobre el quién decide, reclama tanto unas reglas previas y superiores a la decisión de las dos comunidades como un eventual árbitro por encima de las partes que resuelva o limite el conflicto; reclama, en suma, la intervención del Estado.

Respecto a la segunda pregunta, relativa a la justificación del cómo y qué decisiones adoptar en áreas locales, dejo a un lado la discusión sobre la mayor adecuación de algunas formas de democracia directa a ámbitos territoriales menores a los usuales en los Estados, aunque pueda formularse la sospecha de que la aplicabilidad de formas de democracia directa en sustitución de formas representativas sólo sería viable en el ámbito local más estricto, en la ciudad, y siempre que ésta se mantuviera en dimensiones poblacionales muy reducidas. Me interesa más -siempre respecto al cómo y sobre qué gobernar- centrarme en la justificación de la demanda de mayor autonomía local y regional basada en el principio democrático. Junto a una razón fundamental que parece justificar esa demanda aparece al menos una dificultad importante que inclina a limitar su alcance.

La razón fundamental que puede justificar la autonomía democrática de ciudades y regiones -y no espero descubrir ningún misterio- es que la cercanía o proximidad a los problemas puede comportar un mayor grado de legitimidad democrática que la eventual lejanía de la centralización estatal. No es que la cercanía no se preste al riesgo de miopía egoísta del localismo, pero sin duda existen materias en las que la relación entre la población afectada y la decisión a adoptar está tan circunscrita a un determinado territorio que parece demandar la cercanía política, personal y no sólo geográfica, que proporciona la autonomía. Se trata aquí no tanto de razones de mayor eficacia como sobre todo de fomentar la adopción de decisiones queridas, o más directamente controladas, por los afectados, ya que no exclusivos -puesto que tal condición resulta draconiana-, sí principales o decisivos. En términos de justificación democrática, es imprescindible insistir en que la cercanía o lejanía no es sólo, ni principalmente, un factor geográfico -que puede ser muy importante, en cambio, en términos de eficacia, pero que es una cercanía perfectamente accesible para una administración central eficiente-, sino sobre todo un factor político, dependiente del tipo de 
decisiones a tomar y, por tanto, ligado a la preferibilidad de la decisión tomada por los afectados. La condición de esta justificación está en que los llamados a decidir localmente sean los decisivos o principales afectados, por más que esto no sea siempre fácil de interpretar y aplicar. En efecto, esta condición es clara en los extremos y dudosa en las zonas intermedias: mientras es evidente que la política económica o militar no puede ser competencia local, y que la política de obras públicas, transportes, comercio y cultura puede perfectamente sustraerse al Estado en beneficio de su gestión local o regional, existen materias discutidas en las que se lucha por el control exclusivo (piénsese en materia de control judicial, orden público, educación o sanidad). Sin embargo, la justificación de alguna sustracción al poder estatal parece democráticamente clara.

Frente a esa razón, existe una dificultad alternativa, es decir, en términos de justificación democrática, sin entrar aquí tampoco, por tanto, en problemas de eficacia, entre los que destaca la duplicación de la burocracia por una defectuosa distribución de las competencias entre centro y periferia. Esa dificultad de justificación está en que la autonomía local y regional puede producir descoordinaciones y conflictos entre localidades y regiones, siendo uno de los más importantes el relativo a las desigualdades en la distribución de cargas y beneficios. Los problemas surgen solos en el momento en que se dice que en determinadas materias son afectados principales los habitantes de una localidad o región, puesto que las decisiones de éstos (o de sus representantes) pueden sobrepasar el límite y afectar de manera importante a personas ajenas.

Pues bien, el punto al que me interesaba llegar es que tanto la razón de proximidad política «interior» -o hacia dentro de la propia comunidad- de los afectados como la dificultad de la repercusión exterior injustificada, así como el juego entre ambas, exigen una instancia supralocal de decisiones que establezca, de antemano, el marco de la democracia local y un mínimo común a todas las competencias locales (por ejemplo, garantizando los derechos fundamentales) y, a posteriori, una coordinación o control que, negativamente, solucione posibles conflictos $\mathrm{y}$, positivamente, asegure y fomente la cooperación y la solidaridad entre las distintas ciudades y regiones. En suma, la justificación del cómo distribuir las competencias locales presupone la justificación de una instancia coordinadora superior.

En fin, la última pregunta dentro del área local que pretendo formular es la relativa al dónde deben afectar las decisiones o, para decirlo de manera más precisa, a la justificación de dónde 
localizar beneficios y cargas. El problema es fácilmente ejemplificable mediante el caso de la central nuclear que, por ejemplo, el gobierno central, pretende instalar cerca de un territorio determinado sin haber consultado a la población afectada. Aunque pudiera parecerlo por razones de simetría, no es el mismo caso que el de la decisión opuesta de situar un polo industrial limpio (por ejemplo, un «parque tecnológico», como se dice y hace ahora para la industria de nuevas tecnologías). Como tampoco es equiparable a la instalación de una industria molesta pero no peligrosa o a la imposición de un impuesto especial a una localidad o región. En todos estos últimos casos podrá ser admisible la competencia de un poder central -sea estatal o regional- ajeno a la periferia afectada con tal de que la decisión haya sido, como mínimo, imparcial en la consideración de los distintos intereses y, como máximo, inversamente discriminatoria, es decir, en beneficio especial de localidades o regiones menos favorecidas. En el primer caso, en cambio, lo que se discute aquí es si cualquier centro de decisión que no sea propio y exclusivo de los afectados está justificado para atribuir cargas tan graves. Este y otros similares en gravedad serían casos, por tanto, en los que el principio democrático inclina a legitimar el mantenimiento de un ámbito de decisión de carácter local, por ejemplo en forma de veto de tal comunidad tras el correspondiente acuerdo mayoritario entre los individuos o sus representantes.

Resumiendo, en la mayoría de los problemas de ámbito en el área local y regional, para que puedan obtenerse soluciones correctas, debe apelarse a una instancia superior y globalizadora que, de hecho, por una ya larga tradición histórica, no es otra que la organización estatal. Incluso en el caso del reconocimiento del derecho a la autodeterminación termina apareciendo la vieja fórmula del Estado nacional. La cuestión ahora es si los distintos Estados entre sí no podrían ser legítimamente comparados a poderes regionales o locales cuya soberanía debería limitarse en favor de una instancia ulterior que ya no podría ser un Estado igual entre otros, sino un poder internacional con capacidad de regular los conflictos y la cooperación y de arbitrar con eficacia y, sobre todo, justicia. Personalmente así lo deseo, aunque lo crea a duras penas. Es una utopía, si bien acaso una utopía en marcha, de la que son pasos -cortos y vacilantes, es verdad, pero no por ello despreciables- experiencias como la ONU o la tendencia a las uniones continentales y especialmente la europeo-occidental. Y es en el marco de esa utopía en el que pueden plantearse algunos problemas de justificación de los ámbitos de decisión del área de decisión supraestatal. 
El ejemplo de la central nuclear que citaba hace un momento se manifiesta con especial relevancia en las relaciones interestatales, en las que el dónde deben tomarse las decisiones está resuelto en principio en favor del Estado, pero, en mi opinión, no siempre con suficiente justificación. No es sólo que un Estado pueda colocar una central nuclear (o una industria contaminante) junto a la población de un Estado vecino; es que el planeta se ha hecho tan pequeño para las capacidades y riesgos de numerosas actividades que no hace falta ser vecino para resultar gravemente afectado por decisiones y acciones ajenas. El último ejemplo a mano es la explosión de Chernobil, y si se piensa además en decisiones de tipo político-militar o económico, es como para criticar, por haberse quedado corto, a quien dijo que cada año bisiesto nos eligen un presidente en los Estados Unidos. Esto viene a plantear el problema de quién debería decidir internacionalmente en un hipotético Estado mundial.

Es sabido que el Derecho internacional no reconoce como sujetos a los individuos, salvo en concretísimos y limitados campos relacionados con la garantía de algunos derechos humanos. Los sujetos típicos del Derecho internacional son los Estados, y así se manifiesta en los tratados y en las organizaciones y organismos internacionales existentes. Tal presupuesto implica que quienes deciden colectivamente en el área interestatal, al menos formalmente, sean los Estados, bien a través del acuerdo, es decir, mediante tratados, bien -aunque en escasas materias y contadas ocasiones- por votación. En los dos casos se aplica genéricamente, no sin excepciones, el principio de igualdad jurídica de los Estados. Principio que, además de consagrar la soberanía estatal, se diferencia radicalmente del principio democrático estatal e infraestatal: dada la desigual dimensión de los distintos Estados, los individuos ni aparecen como afectados ni resultan representados conforme al criterio de Bentham de que cada individuo vale como uno y nada más que como uno.

Tiene interés, sin embargo, comentar una línea de excepciones existentes en el Derecho internacional que reduce sustancialmente la enorme distancia entre la igualdad jurídica estatal y la igualdad jurídica individual. Me refiero a los casos en que determinados órganos de instituciones supranacionales -como el Parlamento europeo o la Asamblea Parlamentaria del Consejo de Europa- se configuran mediante un número de representantes relativamente proporcionado a la población de los Estados miembros. Sólo en estos casos, me parece, podría decirse que las decisiones adoptadas siguen un principio democrático equivalente al aplicado en órganos estatales o infraestatales de 
representación política. Debe cuidarse de distinguir esta excepción al principio de igualdad de los Estados de otros tipos sustancialmente diferentes. Por no insistir en el derecho de veto de los cinco grandes en el Consejo de Seguridad de Naciones Unidas, hay otros casos en los que se acepta el voto ponderado de diferentes Estados, pero si esto implica una excepción al principio de igualdad formal de los Estados, no por ello se aproxima al principio de la igualdad formal de los individuos: así, el distinto peso de los Estados, según el número de acciones suscritas, en un organismo internacional de cooperación financiera como el Fondo Monetario Internacional es similar al funcionamiento de una junta de accionista de una sociedad anónima y no tiene nada que ver con el criterio democrático tal y como se aplica y se debe aplicar en la política.

A mi modo de ver, una organización internacional centralizadora que pudiera afrontar democráticamente los problemas comunes a la humanidad -especialmente en materias de seguridad, economía y derechos humanos- debería seguir el camino de la igualdad individual y no estatal. No hace falta argumentar mucho para comprender que en una organización semejante Estados Unidos, la Unión Soviética o la India no merecerían el mismo peso que Luxemburgo, Costa de Marfil o Haití. Así pues, tanto por la afirmación del criterio individualista típico de la tradición democrático-liberal como por la negación de que el criterio «Un Estado, un voto» sea propiamente democrático, la conclusión es que también las decisiones internacionales, para ser democráticas, deberían adoptarse mediante un sistema de representación de la población, todo lo ponderado que se quiera, pero representación de individuos a fin de cuentas. Casi viene a reconocerlo así un filósofo político como D. D. Raphael, que, sin embargo, no oculta sus prejuicios discriminatorios hacia los países y poblaciones del tercer mundo (que en número de habitantes es el primero). Raphael sostiene que «la opinión mundial no puede evaluarse en términos de población mundial» y termina defendiendo una «democracia limitada» o «cualificada» para la esfera internacional. Su razón fundamental, que no tiene inconveniente en estimar aplicable a los sistemas políticos nacionales, es que el derecho al voto exige «un grado razonable de conocimiento y educación» ${ }^{11}$.

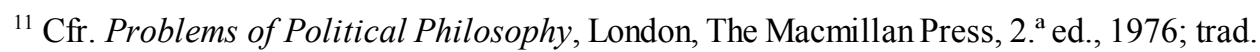
cast. de María Dolores González Soler, por la que se cita, Problemas de filosofía política, Madrid, Alianza Editorial, 1983, págs. 176-177. 
Se debe reconocer que este argumento no deja de tener su fuerza, pues el principio de que cada uno tiene derecho a participar en las decisiones que le afectan exige responsabilidad y, por tanto, un mínimo de formación e información que permita conocer qué le afecta a cada uno y a su comunidad y cuáles son las alternativas a elegir o decidir. Dicho de otro modo, para que una decisión o elección sea informada y propiamente una decisión o elección y no un sorteo o un juego, hace falta que quienes eligen tengan un cierto conocimiento previo. En realidad, esta es, me parece, la única razón fuerte por la que se niega el voto a los menores, puesto que si no fuera exigible un mínimo de responsabilidad y formación no se entendería por qué en ningún lugar se rebaja la edad del voto hasta, pongamos, los seis o siete años, cuando ya existe cierta capacidad de decidir.

Sin embargo, hay que tener en cuenta dos órdenes de problemas. En primer lugar está el peligro de que el criterio anterior sea interpretado o aplicado con parcialidad o, simplemente, de manera incorrecta. Por un lado, cuando esa argumentación se utiliza para justificar una variedad del sufragio censitario -basado ahora no en la propiedad privada, sino en la educación- es apropiada la acusación de discriminación injusta, es decir, de parcialidad: es el caso de algunas leyes electorales que, si no me equivoco, se han aplicado hasta hace no mucho en algunos Estados del sur de la Unión y que afectaban en especial a los negros. Y, por otro lado, cuando se utiliza para justificar la permanencia en un país de un sistema no democrático -lo que resulta familiar para quienes hemos vivido en el franquismo- la argumentación, aparte de sospechosa de parcialidad, puede ser también incorrecta si no resuelve la objeción de que una forma fundamental de educación política la suministra precisamente el ejercicio de las libertades y derechos democráticos.

El segundo orden de problemas se presenta una vez supuesto que el criterio se interpreta y aplica con imparcialidad y corrección. Aun así, la razón aducida por Raphael no tiene en cuenta varios factores. Primero, que la suficiente información y conocimiento como condición del voto ha sido y sigue siendo más un ideal que una realidad, incluso en los países más desarrollados política y democráticamente: si esto es así, ¿por qué exigir más a otros de lo que nos exigimos a nosotros mismos? Una segunda razón que justifica mantener el sufragio universal es que la ecuación entre conocimiento suficiente para participar o decidir y conocimiento o formación intelectual está lejos de ser perfecta: así como hay personas analfabetas perfectamente sensatas e informadas en lo fundamental para saber lo que les conviene, en 
todos los parlamentos hay representantes políticos perfectamente formados intelectualmente que votan lo que dice su partido sin haber oído o entendido una palabra de lo que se debate. $\mathrm{Y}$, en fin, enlazando con lo anterior, aunque los analfabetos informados y los licenciados que votan de oídas fueran un caso marginal, el argumento de Raphael no tiene en cuenta la función canalizadora de las organizaciones de representación política, en especial de los partidos, en la información y formación de los afectados. Canalización no siempre perfecta, por supuesto, pero la menos mala que se ha inventado para practicar la democracia en grandes áreas. Así pues, si se piensa que en un no imposible futuro pudieran irse creando instancias de control internacional que deberían ser democráticas, no hay razón para aplicar un principio distinto al de la representación por sufragio universal y a través de organizaciones de canalización similares a los actuales partidos políticos.

Para concluir, como tal vez muchos lectores vengan pensando que soñar es gratuito -en los dos sentidos de la palabra-, me excusaré (y acusaré manifiestamente) diciendo que señalar las dificultades prácticas de un mayor control internacional y hacer previsiones pesimistas al respecto es tarea fácil y obvia que he dado y doy por descontada. No tengo inconveniente en reconocer la magnitud del salto desde una situación internacional como la actual hasta una organización mínimamente centralizada, que puede llamarse Estado mundial, salvando que no tiene por qué seguir un modelo calcado al de los actuales Estados. Como tampoco tengo inconveniente en reconocer que los pasos desde la actual realidad hasta esa otra deberían ser lentos y cuidadosos, de modo que la construcción de un Estado mundial verdaderamente democrático ni podrá ser, si lo es alguna vez, labor de un día, ni estará libre de ensayos, errores y rectificaciones. Pero reconozco todo eso con una sola condición: que quienes creen en el método democrático y en sus valores reconozcan también que la democracia estatal debería ser sólo una etapa y no una meta con la que conformarse, de modo que sigue habiendo un camino por recorrer que va desde la democracia local a la democracia mundial. 